\title{
SAFE COMMUNITIES THROUGH ENVIRONMENTAL DESIGN
}

\author{
DOI: 10.18485/arh_pt.2020.7.ch13
}

\section{_ Giovanni Sergi}

Architect and City Planner freelance, strada del Cavallo 81/B

Portone 60019 Senigallia (An) Italy, sergi.giovanni.pietro@gmail.com

\begin{abstract}
The "Sustainable cities and communities" is one of the 17 objectives defined in September 2015 by the United Nations Development Program for sustainable development to be achieved by 2030. In particular, it highlights the need to be able to make available to all the populations of the globe by 2030 ".... universal access to safe, inclusive and accessible, green and public spaces, in particular for women and children, older persons and persons with disabilities."
\end{abstract}

In many countries central and local authorities have worked to implement concrete measures in order to make urban environments safer. To sum up several measures have been implemented among which tools for urban planning to tackle deviant behaviours of some social groups. One of the elements characterising urban policies is the systematic cooperation between public authorities in charge of urban planning, real estate companies and experts in security issues.

In Italy some interesting experiences regard the Municipality of Reggio Emilia, Varese, Padua, Genoa, Piacenza and some other urban areas. It can be argued that over the past few years, the following approaches have been used in Italy, with alternate results: 1) national and local legislation and administrative decisions by Municipalities to increase safety and security. This framework includes ordinances issued by Mayors to regulate specific problems such as the use of public areas, the opening/closing time of shops and many other issues; 2 ) some initiatives regarding urban planning aiming at changing and creating urban areas to improve the safety of areas having different dimensions and functions: a square or a road, a new or already existing residential settlement; 3 ) some initiatives based on the model of Smart City which give the opportunity to use new technologies in a systematic way.

In this paper we will present in detail the initiatives recently taken by two important Italian Municipalities with regard to the problem of urban safety: the Municipality of Reggio Emilia which has 172,000 inhabitants and the Municipality of Piacenza which has 104,000 inhabitants.

KEYWORDS _ safe urban environments, sustainable

development, urban settlements, Reggio Emilia, Piacenza

\section{INTRODUCTION}

For many years Italian cities of different sizes have had to deal with the issue of urban safety due not only to traditional crime but also, increasingly, to episodes of petty crime, vandalism, youth deviance, drug abuse and other problems.

The lines of intervention developed by the Central Institutions and the Municipal Administrations 
concern, in general, the social prevention in areas and social groups at risk of crime, the requalification of areas and public spaces affected by critical situations, together with actions of repression through the Law Enforcement Agencies and the Local Police (Acierno, 2003). State and Municipal Administrations are well aware that a city cannot only be functional and equipped with urban spaces of good architectural quality but it must also be and appear safe. The disciplinary knowledge of urban sociology, anthropology, architecture and urban planning together with criminology and crime mapping help to address the problem of urban safety by providing effective tools for analysis, proposal and monitoring (Fasolino, 2018 and Ummarino, 2013).

\section{THE DEBATE ON URBAN SAFETY. FROM THE STUDIES OF THE CHICAGO SCHOOL IN THE 1920S TO THE 2017 INTEGRATED URBAN SAFETY PLANS IN ITALY}

The first discussions on the relation between crime and the urban environment date back to the Chicago School, which can be placed in the area of urban sociology. These studies were carried out in the period 1920-1940. The results of these experiences were introduced in Italy with the translation in 1967 of the book "The City" by Park Burgess McKenzie published in 1925.

In the USA, anthropologist Jane Jacobs published in 1961 "The Death and Life of Great American Cities" which offers a consideration on the relationship between urban planning and safety built on an in-depth analysis of a neighbourhood in New York. Jane Jacobs' theory can be summed up in two concepts. The first factor of safety for a neighbourhood consists in the presence of activities and movement of people as well as the presence of windows overlooking the streets. The second concept concerns the inhabitants' ability to identify with the urban environment they live in.

In this case, the citizen defends and respects the environment he feels as something belonging to him. Jane Jacobs analyses the spontaneous practices of control of the urban territory and relates them to the shape of buildings and public or semi-public spaces.

Following the publication of the highly successful book "Death and Life of Great Cities" at Columbia University in 1970, an interdisciplinary work team was created, coordinated by architect Oscar Newman, to transform Jane Jacobs' analyses into operational design guidelines. At that time, the problem of safety in public housing districts inhabited mainly by African Americans was particularly serious. Oscar Newman's research group was supported both by Columbia University and by the Housing and Urban Development, the important Federal Department dealing with urban issues.

Newman's research group studied spaces in New York's social housing districts and published "Defensible Space" in 1972, the first book to address the problem of designing safe urban space. According to Newman, the safety of an urban environment can be achieved by designing places so that criminal activities have fewer chances to thrive.

Starting from the theses of Jane Jacobs and Oscar Newman, several studies and experiments have been carried out on how to design buildings, neighbourhoods and public spaces to achieve a good level of safety in urban space.

This experiment has been supported by the U.S. Department of Justice and involved Canada and Great Britain. This range of experiences is called Crime Prevention Through Environmental Design CPTED and in the 80 s and 90s gave impulse to applied experiences, conferences, research projects and scientific publications in the Western countries (Coccoi, 2014).

European countries, apart from Great Britain, are not involved in the development of the Crime Prevention Through Environmental Design disciplinary sector. Interest in the issue of safety in cities was highlighted at a conference organised by the Council of Europe in 1989 on "Stratégies locales pour la reduction de l'insécurité en Europe". Since then, environmental prevention has started to spread throughout Europe, giving rise to a wide range of initiatives. To sum up, it can be argued that many European countries give great importance to prevention in connection with the local police, whereas little attention is given to the issue of safety in the urban space.

At the end of the nineties the idea arose to draw up a set of rules on crime prevention and urban design and in 2007 the European Committee for Standardisation CEN published the European standard 
"Prevention of crime through urban planning" CEN 14383. The effect of this standard has been to integrate the concepts of crime prevention into the technical and cultural framework of planning and design in the EU countries (Cardia, 2011).

The standard CEN 14383 contributed to highlight the three key elements to ensure safety in urban areas: urban planning, urban design and the management of urban spaces.

Today in Italy, Decree Law No. 14 of 20 February 2017, converted into Law No. 48 of 2017, introduced urgent provisions on urban safety in cities, providing for the adoption of integrated urban safety plans by the Municipalities (Comune di Firenze, 2018 and Regione Toscana, 2018).

\section{THE PROBLEM OF URBAN REQUALIFICATION IN THE AREA OF THE REGGIO EMILIA RAILWAY STATION}

The Station Area was mainly built close to the Old Town in the seventies with medium-level buildings. Strong speculative tensions together with the typical dynamics of an area around the railway station and the considerable migration flows have led to a social situation characterized by strong tensions and close to collapse.

The area has 31 streets with about 6,250 inhabitants. In this area the percentage of foreign residents is $53 \%$ compared to $16.8 \%$ in the municipal area. In some important streets such as Via Turri and Via Paradisi foreign residents reach $77 \%$. As a result, there is a huge social problem.

Through a process of participatory planning, a "Covenant of coexistence" has been developed, signed by the Municipality, citizens and social organizations.

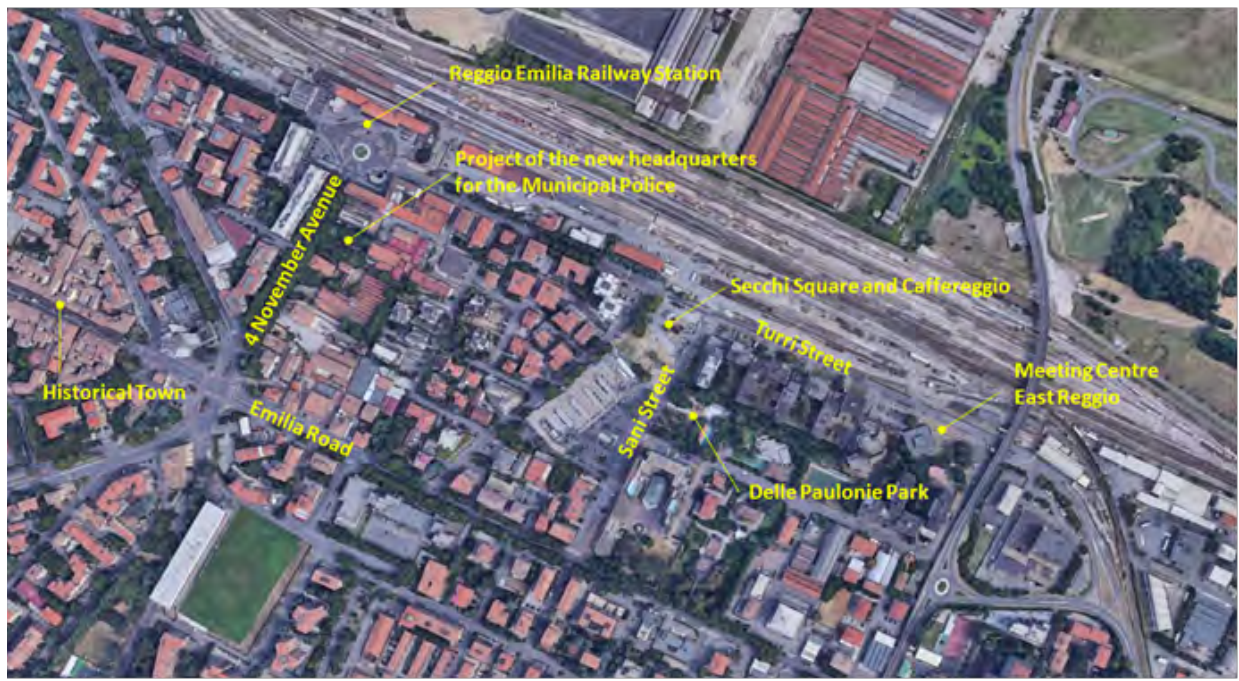

_ Figure 3: Reggio Emilia. Railway Station area: some of the planned or implemented measures. Source: Google Maps, 2019

The objective of the Covenant is to ensure that the Station Area remains integrated into the territory and social dynamics of the city.

The Municipal Administration followed four basic principles:

The first one is related to the role of the Law Enforcement Agencies: 1. Establishment of an organisational panel with Carabinieri, State Police and Municipal Police 2. Monitoring of the territory by the Municipal Police moving on foot to operate in the areas around the Station.

IV Novembre Avenue will host the construction of the new Municipal Police headquarters in order to intervene more effectively in the Station area. 3. Prohibition on the sale of take-away alcoholic 
drinks after 5.30 p.m. in some streets close to the Station. 4. Activation of a large and widespread video surveillance system managed by the control centres of the Carabinieri and Police.

The second principle is related to the quality of urban design: 1 . The relationship between urban planning and safety was considered as a key element 2. On Domenica Secchi Square near the railway station a large green area was created with a high quality urban furniture with the inclusion of a kiosk, the Caffereggio, where no alcoholic drinks are sold. This area previously known as "Lucchetto" is the result of a redevelopment activity that led to the demolition of existing decrepit buildings 3 . Urban redevelopment through new interventions focused on two parks in the area affected by several problems. Particularly interesting is the project for the new "Parco delle Paulonie" covering a surface of 3,200 square meters near the station between Via Paradisi and Via Sani 4. Great importance to maintenance activities in the railway station area to show attention towards local inhabitants.

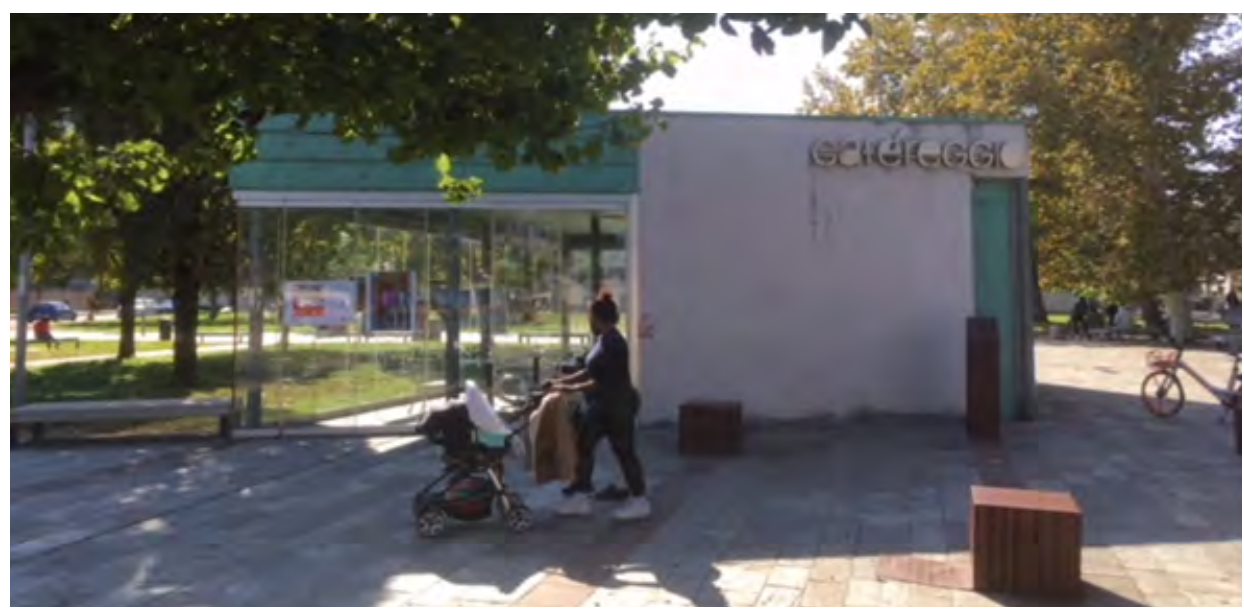

_ Figure 4: Municipality of Reggio Emilia, Secchi Square and Caffereggio kiosk near the Railway Station. Photo: G. Sergi, 2019

The third principle is the development of the network of services as an important factor for meeting, integration and dialogue: 1. Interventions with services focusing on city maintenance: from public transport to urban hygiene 2. Interventions of a socio-cultural, welfare and educational nature. Two examples: the nursery school "Oasis" in Via Caravaggio 2 and the educational facility for post-adolescents under risk of deviance called "Spazio Raga"and located in the "Meeting Centre Reggio Est" 3. Specific projects against degradation aimed at addressing the issue of alcohol abuse in some areas

The fourth principle is related to the activity of social prevention and cultural workshops: 1 . The central element is represented by the "Meeting Centre Reggio Est" founded as an ARCl club in Via Turri 49 which is a reference point for all actions carried out in the area. Among these actions an Incubator of Solidarity Economy IES to promote social inclusion 2. Opening of a "Social Mediation Centre" in Via Turri 27 available to citizens and social workers. They work to prevent conflicts in private spaces such as condominiums. It is also a centre to host conflict mediation and residential education projects. 3. A system of labs dedicated to music, dance, theatre, photography etc. 4 . Creation of a Festival that reflects these cultural activities within the territory.

Some phenomena that are taking place, such as the sale of houses and shops by inhabitants who have lived here for decades to new immigrant residents, represent a reality for which the Municipality cannot take measures. There is a clear need for general policies that give new intervention tools to the Municipal Administration together with the certainty of adequate resources (Corradini, 2014). 


\section{THE PROBLEM OF URBAN SAFETY IN THE CITY OF PIACENZA}

In 2019 the Municipality of Piacenza had a resident population of 104,000 inhabitants with a slight growth trend due to a good productive fabric both in agriculture and industry and a lively activity in the tertiary sector also due to its favourable location within the motorway and railway network between Milan and Bologna.

The Municipal Administration of Piacenza has been committed in recent years to carry out projects aimed at fighting crime, vandalism, child deviance and to resolve social and cultural conflicts due in part to the presence within the municipal territory of 20,000 immigrants from Eastern European and non-European countries.

Over the last two years, the Municipal Administration has drawn up an action programme aimed at addressing the various problems that have caused concern within a large part of citizens towards the problems that can be defined within the category of urban safety.

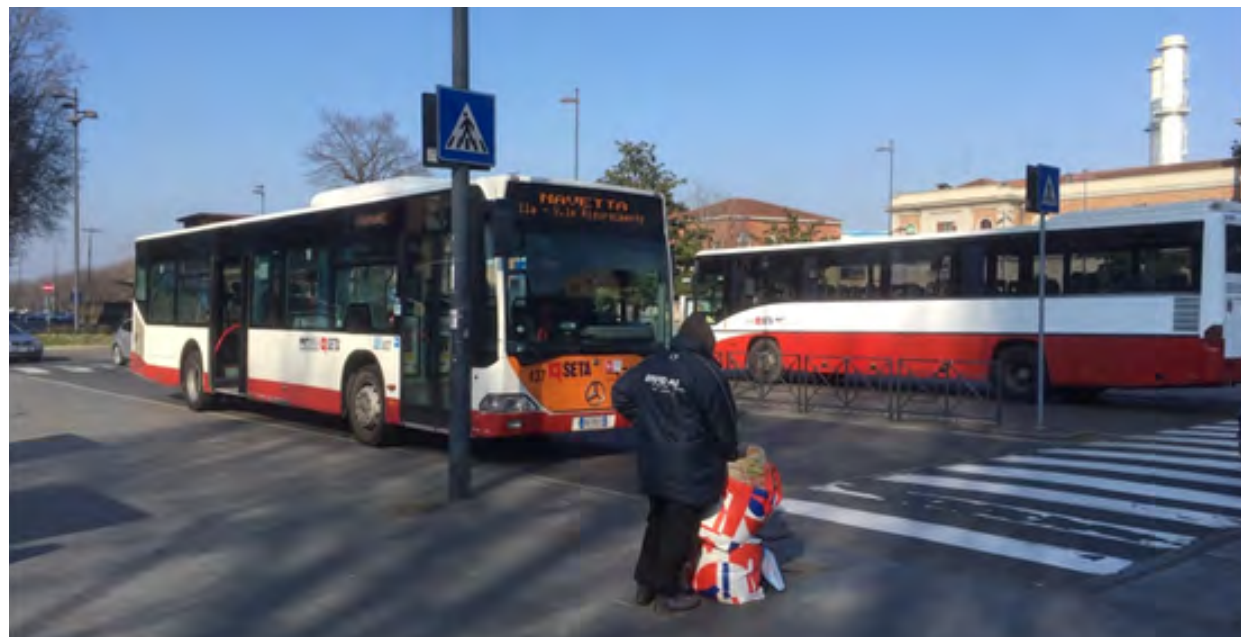

_ Figure 5: Municipality of Piacenza, Marconi Square and Seta company bus stop at the Railway Station. Photo: G. Sergi, 2020

These actions refer to two types of intervention.

The first concerns a change in municipal rules that can take action against the most obvious manifestations of petty crime, youth deviance and vandalism.

These are new rules introduced in October 2018 as part of the Municipal Urban Police Regulations, which reduce the possibility of selling and consuming alcoholic drinks in certain areas of the city and at certain times.

Specifically, article 18 of the Regulation has been modified with an amendment that allows, thanks to specific resolutions of the Municipal Council, to identify areas in the municipal territory where 1. it is forbidden to consume alcohol or drinks in glass bottles on public land at certain times 2 . it is forbidden to remain open beyond 9 p.m. for premises without adequate internal space for the administration of drinks such as ethnic stores or beyond midnight for those premises that have a suitable space such as bars or restaurants 3 . it is forbidden to sell for take-away alcohol or drinks in glass bottles at certain times.

Other actions have been developed because city has to face a series of critical areas in terms of urban safety that can be identified in some sparsely populated districts, in the areas around some schools, on some bus lines for the transport of students, in the area around the Railway Station of Piacenza i.e. on Marconi Square and inside the Margherita Gardens. The situation around the Railway Station is particularly complex due to the confluence of numerous public service bus lines, the 
presence of an important shopping centre and the Margherita Gardens, which have become one of the stopping points for homeless people.

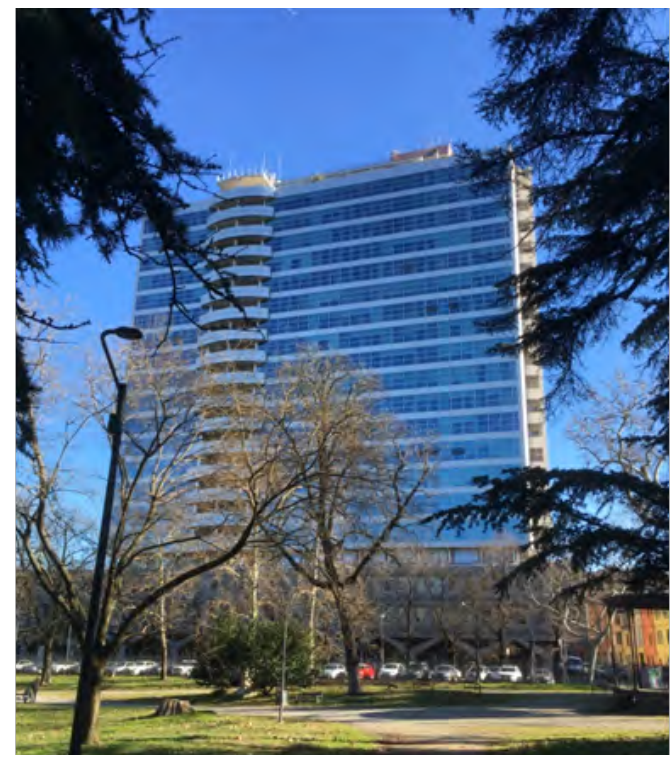

__ Figure 6: Municipality of Piacenza, Margherita Gardens and residence of the Mille. Photo: G. Sergi, 2020

In 2018 the Municipal Administration in agreement with the Prefettura (Territorial Government Office) of Piacenza outlined a "Pact for the implementation of urban security" which received substantial funding from the Ministry of the Interior to set up a video surveillance network covering the entire city and consisting of 40 cameras. Of these, 11 will be cameras capable of reading car number plates. The other 29 will be cameras capable of monitoring a part of the urban territory. The points where the cameras will be installed have been decided by the Municipality together with the Prefettura (Territorial Government Office).

The "Safe Schools" project has been developed by the Municipality of Piacenza together with the Education and Law Enforcement Authority. The aim of this project is to combat drug use among students, vandalism and bullying. Among the measures carried out is the placement of seventy cameras on buses carrying students. In June 2018 , the Municipality of Piacenza, together with the Municipal Residential Building Agency ACER, developed and implemented a plan to increase the safety of the inhabitants of Barriera Farnese, a residential district inhabited mainly by low-income families who have been affected by numerous episodes of youth petty crime. The Municipal Administration, together with ACER, has installed 16 video surveillance cameras inside the Barriera Farnese district to provide a deterrent for those gangs of petty criminals who not only produce annoying noises until late at night but make it difficult for the inhabitants to return home in the evening.

In 2019 the Municipality of Piacenza and ACER carried out a project to place another 16 surveillance cameras in the district of Ciano inhabited by middle-income families. These cameras are paid by the inhabitants of the apartments with a small monthly fee.

\section{CONCLUSIONS}

In Italy, the Constitution and other fundamental laws provide that urban security and public order are a primary responsibility of the Central State which operates through the Forces of Law and Order: Carabinieri, State Police and Guardia di Finanza (Finance Guard) coordinated by the Ministry of the 
Interior and the Prefects on a provincial scale. A series of laws promulgated by the Regions in recent years have given greater power to the Municipal Administrations with regard to urban security. A recent and important Italian law: number 48 of 2017 "Urgent city security provisions" has tackled the problem of security in urban areas and has established the Plans for integrated urban security that include, among the many possible interventions, interventions capable of modifying the urban conformation of some critical points of the cities in order to guarantee greater security for citizens. In the Italian reality, two different types of approach to the problem of urban safety have emerged in recent years.

A first approach that we could define as "conservative" as the case of Piacenza where a lot of importance is given to security systems based on video and audio technologies as well as some social and urban design interventions.

A second approach that we could define as "progressive" as the case of Reggio Emilia where great importance is given to the issues of social integration of groups that present behaviors characterized by marginalization phenomena as in the case of ethnic minorities. The theme of social support has, in this approach, much more importance than repressive measures. Obviously, available technologies such as video surveillance are also used, but interventions capable of regenerating urban spaces in order to favour social integration are preferred.

While the Municipalities of the Anglo-Saxon Countries that follow the model of the "Crime Prevention Through Environmental Design" tend to develop a Municipal Plan for urban security in Italy, today, the line followed by the Municipal Administrations, in agreement with the Prefectures, is that of leaving to the Police Force the primary responsibility of guaranteeing urban security. The Municipalities deal with the issue of urban security by collaborating with the Police and implementing video surveillance systems developed in agreement with the Prefectures. Municipalities also integrate the work of the Police through interventions in the field of social policies and in the urban redevelopment of areas with obvious critical issues in terms of urban security. It seems that with a certain gradualness in the coming years in Italy too, integrated plans for urban safety will be realized.

In recent years in Italy the debate on urban security issues has been very articulated. Universities, municipal administrations and cultural associations dealing with urban safety at national level have participated with interesting contributions. Italian urban planners are realizing that a city can not only be functional, beautiful and able to contribute to the balance between different social groups but must also be safe.

\section{REFERENCES}

- Acierno, Antonio. 2003. Dagli spazi della paura all'urbanistica per la sicurezza. Firenze: Alinea Editrice

_ Cardia, Clara, and Carlo Bottigelli. 2011. Progettare la città sicura. Milano: Editore Hoepli

- Coccoi, Sandro. 2014. Città, obiettivo sensibile. Disegno urbano e sicurezza. Milano: Libraccio Editore

- Comune di Firenze. 2018. Patto per Firenze sicura. Patto per la sicurezza urbana. Firenze

_ Corradini, Franco a cura di. 2014. Dalla città all'Europa. Strategie di sicurezza urbana. Città di Reggio Emilia: Edizioni Nuova Prhomos

_ Fasolino, Isidoro, and Francesca Coppola, and Michele Grimaldi. 2018. La sicurezza urbana degli insediamenti. Milano: Franco Angeli Editore

- Jacobs, Jane. 2009. Vita e morte delle grandi città. Torino: Giulio Einaudi Editore

_ Park, E.Robert, Ernest W. Burgess and Roderick D. McKenzie. 1967. La città. Milano: Edizioni di Comunità

_ Regione Toscana and ANCI Toscana. 2018. Toscana Sicura. Libro bianco sulle politiche regionali di sicurezza urbana. Firenze

_ Bravo, Fabio. 2014. "L'efficacia del crime mapping per la sicurezza urbana: il caso di Enfield (Londra)." Rivista di Criminologia, Vittimologia e Sicurezza Vol.VIII- no. 1 (Gennaio-Aprile): 38-73

_ Ummarino, Alessandro. 2013. "Una introduzione ai software per il crime mapping." Rivista di Criminologia, Vittimologia e Sicurezza Vol.VII- no. 1 (Gennaio-Aprile): 147-59 